\title{
Is Overall Equipment Effectiveness (OEE) Universally Applicable? The Case of Saint-Gobain
}

\author{
Karim Charaf ${ }^{1} \&$ Huifang Ding ${ }^{1,2}$ \\ ${ }^{1}$ Groupe ISCAE, Morocco \\ ${ }^{2}$ Burgundy School of Business, Dijon, France \\ Correspondance: Karim CHARAF, Groupe ISCAE, Km 9,500 Route de Nouasseur BP. 8114 - Casablanca Oasis, \\ Casablanca, Morocco. Tel: 212-5223-35482. E-mail: kcharaf@groupeiscae.ma
}

Received: October 8, 2014

Accepted: December 1, 2014

Online Published: January 25, 2015

doi:10.5539/ijef.v7n2p241

URL: http://dx.doi.org/10.5539/ijef.v7n2p241

\begin{abstract}
In the context of a global competitive environment, industrial companies have to pursue continuous performance improvement, leading to the popularity of Lean Manufacturing throughout the world. Overall equipment effectiveness (OEE) is considered the relevant performance measurement tool, which is able to take into account a machine's availability, performance and quality. Therefore, many firms have attempted to introduce this tool in their industrial units.

This article consists of a study of the OEE metric application range in real manufacturing lines, to develop an understanding of the related challenges for production managers, financial controllers and companies.
\end{abstract}

Keywords: lean manufacturing, overall equipment effectiveness (OEE), performance measurement tools, OEE metric application, challenges

\section{Introduction}

Due to intense global competition, manufacturing companies have to optimize their productivity to meet customers' changing expectations and finally to gain competitive advantages towards long-term survival. This strategy is totally in accordance with the lean manufacturing perspective.

As indicated by Fleischer et al. (2006), the manufacturing firms' competitiveness depends on the availability and productivity of their production equipment. This situation has led to the need for a rigorously defined performance measurement system for manufacturing processes. Overall equipment effectiveness (OEE) is considered as one such powerful tool, which is able to measure a machine's productivity by taking into account three essential components (availability, performance and quality) and mapping out the related losses landscape. The OEE tool is becoming increasingly popular and has been widely used as the foundation of industrial performance.

Nevertheless, the richness of OEE metric deployment has not been totally revealed by academics, and its application range in the real world remains vague according to the literature review. On the other hand, the traditional cost accounting systems assigned to formulate business strategy and to plan and control activities and performance improvement need to be updated to take into account the changing nature of competition and manufacturing. The option to include nonfinancial metrics, such as the OEE metric, in a company's controlling system requires that the financial controller gain a deep understanding of the nature of manufacturing and seek to attain the critical factors related to the firm's continuous competitiveness.

The objective of this paper is to study the OEE metric application range in the real manufacturing lines, and to develop an understanding of the related challenges for production managers, financial controllers and companies.

This article is organized as follows. First, we present a literature review. Then, we discuss the methodology used, describing the case study of SAINT-GOBAIN PONT-A-MOUSSON, and finally the results will be analyzed.

\section{Literature Review}

\subsection{Overview of Manufacturing Classifications}

According to Horngren and Foster (2008), "The physical processes of production are the keys to the design of 
cost accounting systems. If the processes change, the cost accounting systems should also change". An overall understanding of the manufacturing process in a plant is a necessity for its financial controller, whose role is to assist the plant manager in performance improvement and strategy materialization.

However, as indicated by Kaplan (1990), in the literature it is difficult to classify manufacturing categories' lack of basic definitions that allow us to characterize production technology concepts beyond notions of "batch manufacturing" and "process manufacturing". Neither is there a widely accepted definition of repetitive and discrete manufacturing, continuous and batch production, even though they are considered common concepts for practitioners. This phenomenon could perhaps be explained by the fact that it is always the engineers or industrialists, having worked in a plant, who devise and evolve the manufacturing process, without updating the literature research studies.

\subsection{From Manufacturing to Performance Measurements}

\subsubsection{Cost Accounting Practices Need to Accommodate the Realities of the Manufacturing Environment}

An interesting aspect in the manufacturing evolution is that it has occurred in the automobile industry. This could perhaps stem from its distinguishing feature - incessant fierce competition between different automobile producers throughout the world. That is why, as pointed out by Sugimori et al. (1977), there are very many different models with numerous variations and with a large fluctuation in the demands of each variation; and every few years, the vehicles are completely remodeled and there are also often changes at a parts level. Confronted by such competition in the product market, automakers have to become better and better by continually improving their performance and responding rapidly to their customers.

As analyzed by Huang et al. (2003), due to intense competition, companies strive to improve and optimize their productivity in order to remain competitive. It is then necessary to elaborate both short-term and long-term plans according to business strategy; to communicate with the personnel and to stimulate them; to provide quantitative evaluation of current performance; to propose potential improvement based on problems identified by previous analysis and finally to materialize the corporate strategy. Kaplan (1984) showed that by 1925 DuPont and General Motors had already developed the ROI performance measurement, budgeting and planning cycles, flexible budgets and many other managerial control practices used today.

What, then, is the exact relationship between manufacturing, the nature of the competition and cost accounting practices? In the literature, many research studies were found which separately consider the production process and cost accounting systems. However, Kaplan (1984) considered that the truth of the interrelation between the competitions in the product market, the production technology used by the firm (e.g. complexity and product mix), the importance of indirect costs, and the production control and cost accounting systems has seldom been revealed. To some extent, this could be explained by the complex nature of the manufacturing process and the variety of cost accounting practices in the industrial world.

Previous research indicates that the design of cost accounting and production control systems depends on the production technology, the importance of overheads and competition faced by the firm (Karmarkar et al., 1989)

As analyzed by Kaplan (1984) through a historical review of the management accounting evolution, the motivation for innovation in cost accounting and managerial control practices has always been driven by the changing nature of industrial competition and devised by engineers and industrialists, having worked in a firm and been confronted by that demand for adaptation.

In conclusion, the evolution of manufacturing leads to the development of cost accounting and the managerial control system. The latter is considered, according to the Chartered Institute of Management Accountants (CIMA, Note 1), to require the identification, generation, presentation, interpretation and use of information relevant to formulating business strategy, planning and controlling activities, decision making, efficient resource usage, performance improvement and value enhancement, safeguarding tangible and intangible assets, and corporate governance and internal control (Bhimani et al., 2008).

\subsubsection{Lean Manufacturing Demands Appropriate Performance Measurements}

Due to intense global competition, a lot of companies have chosen to get lean and adopt this strategy continuous improvement through sustainably declining costs, a continuous quest for perfection, efficiency in production, rapid responses to changing customer tastes and, finally, competitive advantage. Such a strategy needs to be materialized by a performance measurements system, as indicated by Hayes et al. (1989). This would have a profound effect on human behavior: people are more likely to do what you inspect than what you expect.

Is the traditional model still compatible with this new challenge? 
Budgeted performance measurements, which are traditional metrics still practiced in many firms, were developed for mass production. However, as identified by Bhimani et al. (2008), traditional budgeting has the following limitations:

- It extends a method application based on the past into the future by assuming that existing trends will continue;

- The budget overemphasizes a fixed time horizon, such as a year. As a consequence, meeting annual cost targets is considered a key task to be achieved;

- Budgetary concerns are preoccupied with financial measures in the budget period.

As the management accounting must be formulated based on the corporate strategy, in the perspective of continuous improvement, it is more appropriate to set an objective towards perfection, rather than simply being better than the budget. Also, instead of meeting a short-term financial goal set in the annual budget, striving for perfection could stimulate the personnel in the long term. According to Kaplan (1984), the traditional cost accounting model, developed for mass production by 1925, needs to be updated to take into account the changing nature of competition and the demand for internal information.

Secondly, it is possible that managers will find measurements of product quality or productivity are relevant for their decision-making, and persons other than management accountants may provide those measurements. For Kaplan (1984), the option to include nonfinancial metrics in the firm's planning and control system requires management accountants to understand those factors that are most critical to the company's long-term survival. As noted by Fleischer et al. (2006), the competitiveness of manufacturing companies depends on the availability and productivity of their manufacturing facilities. To materialize the lean strategy, it is necessary to take into account those key indicators not included in the financial measures.

Moreover, metrics are usually represented by elaborate and pervasive reports and data. As indicated by Hayes et al. (1989), the complaint of factory managers in many companies is that they are inundated by a blizzard of reports - each conveying a different message, depending on the measures used and whether performance is compared against standards, last year's results, budgets, or industry averages. The business demand leads to the pursuit of integrated and rigorous metrics which can take into consideration several important factors, such as equipment performance, availability and quality.

Hence, new performance measurements should be able to materialize the lean strategy of the continuous quest for perfection, to include key indicators related to manufacturing's competiveness and to facilitate the plant managers' decision making related to performance improvement. Such new metrics should be feasible through tools which are simple and clear, but powerful.

\subsection{Overall Equipment Effectiveness (OEE), Lean Metric of Cell Performance}

\subsubsection{Origin of OEE: the Total Productive Maintenance}

Overall equipment effectiveness (OEE) is described as one performance-measurement tool to materialize the quest for perfection of lean manufacturing into daily practices.

In a lean environment, the negative consequences of machine breakdowns and production disruptions cannot be accepted as they prevent the creation of value for customers and cannot be compensated anymore. Thus, a rigorously defined performance measurement system is indispensable to control such kinds of losses. This is the origin of the Total Productive Maintenance (TPM) concept launched by Nakajima (1988), who believes that it is imperative to continuously improve all operational conditions within a production system by stimulating the daily awareness of all employees. The objective of TPM is to achieve zero breakdowns and zero defects related to equipment, which could lead to improvements in the production rate, reduction in inventory, reduction in costs and eventually increases in labor productivity. As analyzed by Muchiri and Pintelon (2008), this is especially true of highly automated processes.

However, the recognition that machine breakdowns and production disruptions prevent the creation of value for customers is based on the hypothesis that the market could absorb all that is produced. In lean manufacturing, production is not pushed by a series of schedules but pulled by market demand to produce only as much as can possibly be sold. It is more appropriate to interpret the TPM as one of the components of the lean manufacturing system, rather than an individual magic tool. Independently of the integrated system, is the philosophy that machine breakdowns are unacceptable still true? 


\subsubsection{How to Evaluate Cell Performance through OEE}

\section{- OEE: quantitative metric of TPM}

The Total Productive Maintenance (TPM) has devised a quantitative metric tool - overall equipment effectiveness (OEE) - for measuring the productivity of individual pieces of manufacturing equipment at a plant. According to Williamson (2006), OEE assesses the degree to which the equipment is doing what it is supposed to do, based on the availability, performance and quality rate.

Overall Equipment Effectiveness (OEE) is commonly used by manufacturing companies as:

- a performance indicator of equipment utilization;

- a measure of asset or equipment utilization;

- a benchmark (initial performance of a manufacturing plant versus the future OEE values);

- a means to compare line performance across the factory, in order to identify any poor line performance.

\section{- OEE and semiconductor manufacturing}

As indicated by Huang et al. (2003), the OEE concept is becoming increasingly popular and has been widely used as a quantitative tool, which is essential for productivity measurement especially in semiconductor manufacturing operations. This is because it is necessary to have an overview of this kind of manufacturing setting.

The global semiconductor industry is highly competitive, especially with continuous technological innovation requiring a rapid response to demand fluctuation. However, the investment costs of a ready-to-start semiconductor fabrication plant have increased significantly, while the profit margins have been dramatically squeezed. Equipment costs represent about two thirds of total investments.

As analyzed by Konopka (1996), an increase in yield by just a few percent would contribute significantly to the semiconductor producer's ability to recover overheads in the estimated five years' depreciation time allocated to a semiconductor fabrication plant. Moreover, the operating costs for tools are highly important.

Due to the high investment and operating costs, even minimal improvements could result in high cost reduction. Hence, the equipment is of great importance in the overall costs of a semiconductor fabrication plant. This explains the increasing priority the industry is placing on improving the production capabilities of their existing manufacturing facilities; thus, assessing and optimizing the utilization of current capacity becomes a key component for measuring plant performance. As OEE deals with increased productivity of individual pieces of equipment, it meets the demand of the semiconductor industry.

\subsubsection{Search for a Wide Range of Applications in Manufacturing}

According to Huang et al. (2003), quantitative OEE analysis is still in the early stages of development and is limited to productivity behavior of individual pieces of equipment. This is the reason we don't have considerable research studies related to that topic in the literature. Despite that, this study has already cast some doubt about this simple and powerful tool.

\section{- Manufacturing nature}

For Bulent et al. (2000), OEE is beneficial in high-volume process-based manufacture where capacity utilization is a high priority, and stoppages or disruptions are expensive in terms of lost capacity. As identified by Muchiri and Pintelon (2008), in low-volume job shops and some batch processes, the unscheduled production time is high, and failure of one machine could be rerouted to another machine. Thus, the changeover time could not be considered as a loss since the set-up can be done on one machine and production can be continued on another. For production processes with buffers in between, OEE would need to be redefined, since downtime on one process stage does not have a direct consequence for the next stage. The breakdown is not always a loss as we could still create customer value with downstream center. Due to the nature of these processes, deployment of OEE in such a case is not very beneficial.

\section{- $\quad$ Lack of coordination}

Scott and Pisa (1998) indicated that the gains in OEE, while important and ongoing, are insufficient because no machine is isolated. They determined that the manufacturing process is a complex web of interactions between process tools, materials, machines, people, departments, companies, and processes. To overcome this limitation, tools such as Overall Factory Effectiveness (OFE) and Overall Throughput Effectiveness (OTE) have been developed to take into account the performance at the plant level. However, it is difficult to produce a widely 
accepted overall productivity metric. According to Huang et al. (2003), a literature survey indicated that at present there is no single, well-defined, proven methodology for the analysis of overall factory effectiveness.

\section{- $\quad$ Translation of cost to be added}

As discussed before, there is debate as to whether machine breakdowns always represent a loss. For Muchiri and Pintelon (2008), further research should be done to explore the dynamics of translating OEE in terms of cost, making it more significant for management. The process of searching for this answer could be a journey to discover some limitations of OEE towards flexible adaptation and wide-range application. Without a clear answer to that question, it is difficult to persuade people to pursue this form of performance measurement.

\section{- $\quad$ Requirement for data accuracy}

According to Muchiri and Pintelon (2008), the validity and usefulness of the OEE measure are highly dependent on the data collection and accuracy. As reported by Ericsson (1997), accurate equipment performance data are essential to the success and long-term effectiveness of TPM activities. Without reliable data, the different losses cannot be measured and identified, and thus TPM actions cannot solve the core problem or improve the performance. This leads to a lack of credibility among workers. It is therefore important to invest time and money to improve data collection. For this reason some manufacturing companies have automated their collection of OEE-related data to guarantee the data accuracy.

\section{Research Method}

Despite the fact that experimenting with the real production line would be perfect, this is seldom feasible, due to the high cost related to changing a system and considerable uncertainty in a real-world system. According to Huang et al. (2003), simulation analysis is considered the most reliable method to date in studying the dynamic performance of a manufacturing system. Hence, several elaborate simulation models have been developed to deal with numerous variations and to provide estimates of their influence on the system's performance. Because of the lack of such research expertise and work experience in manufacturing, quantitative analysis was not chosen for this study.

As suggested by Kaplan (1984), researchers need to leave their offices and study new measurement systems in a company, which is responding to the changing nature of competition. A qualitative study allows researchers to discover practitioners' experience and to update literature research study; not only to overcome the limitation of simulation models (as it is nearly impossible to reproduce a real-world system) but also to inspire their further elaboration. Thanks to the work in progress of the WCM program in the company, several kinds of stakeholders were willing to share their expertise and work experience related to the manufacturing and implementation of WCM and OEE, etc. in real production lines for the benefit of this study.

Therefore, the research work at SAINT GOBAIN PONT-A-MOUSSON was performed within the framework of qualitative study. The objectives of this approach consisted of shedding light on the topic of quantitative analysis OEE through a qualitative view: to discover the origin of OEE implementation in a real plant; to determine the main advantages related to performance measurements through OEE; to gain an understanding of its practice in a real workshop and plant; to identify potential difficulties throughout the implementation process and to understand their causes; to gather the opinions of different stakeholders regarding this metric; to find out the answer to our research question "Is Overall Equipment Effectiveness (OEE) universally applicable?"; and finally, to attempt the potential proposition within the company.

Specifically, at SAINT GOBAIN PONT-A-MOUSSON the research study was conducted through two strategies; observations structured around weekly meetings organized by the Iron and Energy department for the Industrial Performance Pillar of the WCM program, and individual interviews with the principal stakeholders in the Pillar. The study was based principally on the latter.

\subsection{Observation through Weekly Meetings}

The researchers had the opportunity to attend the weekly meetings organized by the Iron and Energy department for the Industrial Performance Pillar of the WCM program. Non-participating observations were made during 13 weekly meetings. These meetings lasted usually at least 1 hour. The fact that their program WCM was still in the early stages of development enabled the researchers to attend talks related to such topics as lean manufacturing and OEE. Interesting arguments were put forward during the meetings by experienced participants presented in Table 1. 
Table 1. Study participants

\begin{tabular}{llr}
\hline \multicolumn{1}{c}{ Name of participant } & \multicolumn{1}{c}{ Post } & Employer \\
\hline $\begin{array}{l}\text { Jean-Sébastien PFEIFFER } \\
\text { Julien BONNET } \\
\text { Olivier RISSE }\end{array}$ & $\begin{array}{l}\text { Manager of Iron workshop at the Plant PONT-A-MOUSSON } \\
\text { Lean manufacturing consultant } \\
\text { Financial controller at the Plant PONT-A-MOUSSON }\end{array}$ & SAINT-GOBAIN PONT-A-MOUSSON \\
SOLVING EFESO & SAINT-GOBAIN PONT-A-MOUSSON \\
Pascal FRANÇOIS & Manager of Energy shop at the Plant PONT-A-MOUSSON & SAINT-GOBAIN PONT-A-MOUSSON \\
Patrick JACQUOT & Manager of Sinter workshop at the Plant DIEULOUARD & SAINT-GOBAIN PONT-A-MOUSSON \\
Rémy COLIN & WCM coordinator of the Iron and Energy department at the & SAINT-GOBAIN PONT-A-MOUSSON \\
& Plant PONT-A-MOUSSON & \\
Thierry BERTINOTI & Manager of the Iron and Energy department (Note 2) at the & SAINT-GOBAIN PONT-A-MOUSSON \\
& Plant PONT-A-MOUSSON &
\end{tabular}

The Industrial Performance Pillar of the Iron and Energy department had attempted to introduce the OEE tool at the Iron workshop. It was during the weekly meetings that participants exchanged their views regarding the question: Is the OEE metric suited to the Iron workshop? After discussions, they came to the conclusion that the OEE measurement was not applicable for the Iron workshop, as it could not represent the real productivity of the cell.

\subsection{Individual Interviews}

To gain a further understanding, individual interviews were conducted to clarify the topic related to OEE. Moreover, talks with different stakeholders of the Industrial Performance Pillar of the Iron and Energy department allowed us to directly discover their rich work experience and to gather their personal opinions on the lean quantitative metric.

To get an overall vision, three kinds of stakeholders were interviewed:

1) Production managers

2) WCM coordinators

3) Financial controller

They are presented in Table 2 .

Table 2. The interviewed study population

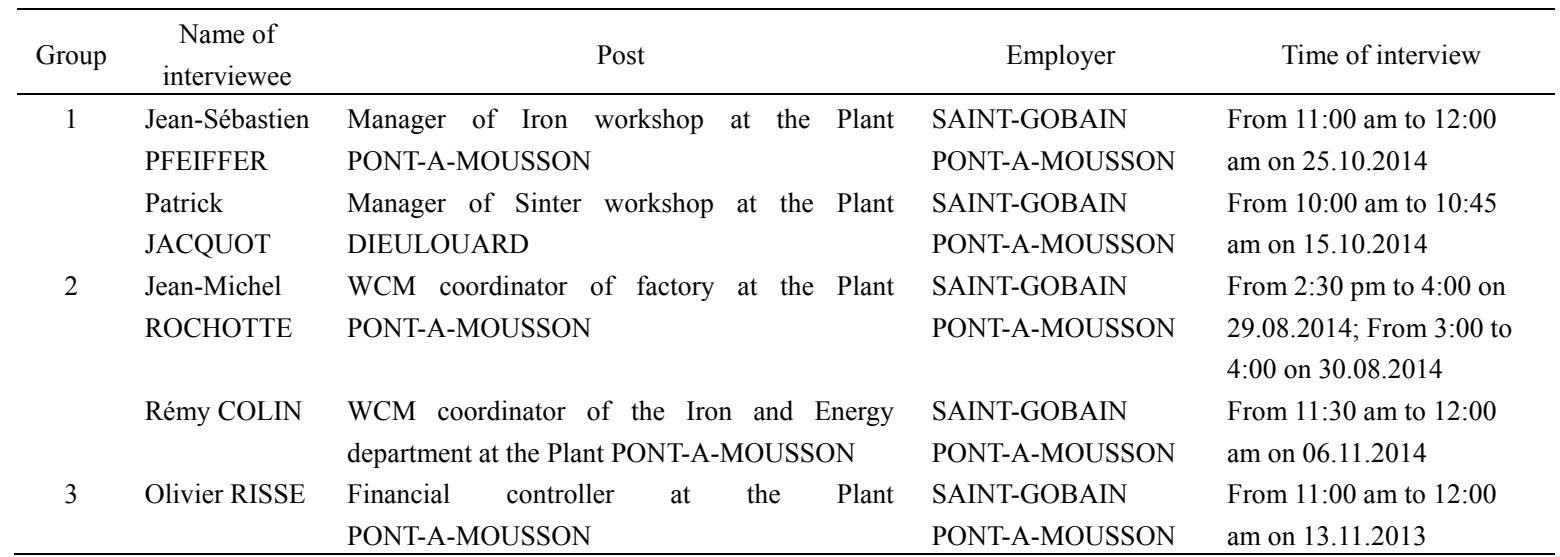

The interviewees are participants in the Industrial Performance Pillar of Metal and Energy department, except Jean-Michel ROCHOTTE. As the former supervisor of Coating at the 8M Casting workshop and the WCM coordinator of the 6M Casting department and of the factory, Jean-Michel ROCHOTTE provided a supervisor's view of the OEE, explained the manufacturing process at the $8 \mathrm{M}$ workshop and shared with us the challenges that the factory faced with the WCM's development.

Five semi-structured interviews were then conducted based on a general interview guide, founded on trust and specified case studies, while a few different topics were addressed, depending on the different stakeholders. In 
the general interview guide, followings topics were investigated: which tool that you would like to have to measure a workshop's performance? Why you wanted to implement the tool OEE? In which stage are you on the project WCM and the implementation of the tool OEE? Have you ever met any difficulties during the implementation? Why? Have you ever found out a relevant solution? Do you think the tool OEE could work in any workshop? Is-it interesting to take into account the concept of cost in the tool OEE? Will you continue to use this tool? Explanation on production workflow were given by Jean-Michel ROCHOTTE and Jean-Sébastien PFEIFFER during individual interviews. All the interviews were recorded with a Dictaphone and transcribed manually.

\section{Background}

\subsection{Company Presentation}

SAINT-GOBAIN Limited, having 350 years of history, is the world leader on habitat and construction markets. It designs, manufactures and distributes building materials and provides innovative solutions. The Group is organized around four sectors: Innovative Materials, Construction Products, Building Distribution and Packaging. The total sales of the Group were worth 43.2 billion euros in 2012.

Contributing 25\% to the Group's total sales, the Construction Products Sector provides solutions dedicated to acoustic and thermal insulation, exterior wall covering, roofing, interior and exterior fittings and piping. Its diversified business base possesses a portfolio of high-profile brands like Isover, Weber, British Gypsum and PONT-A-MOUSSON.

SAINT-GOBAIN PONT-A-MOUSSON represents the Pipe Activity in the Construction Products sector of the Group. Founded in 1856, SAINT-GOBAIN PONT-A-MOUSSON, a world leader in complete ductile cast iron pipeline systems, designs, produces and sells a complete range of solutions dedicated to the transportation of water. In 2012, the sales were worth 675 million euros, of which 52\% were from export (Note 3).

\subsection{Plant SAINT-GOBAIN PAM in PONT-A-MOUSSON and Its Performance Measurements System}

SAINT-GOBAIN PAM's plant in PONT-A-MOUSSON (PAM Plant for short) is considered the biggest ductile cast iron pipe production unit in the world with an area of 120 hectares (including 13 hectares of industrial buildings), personnel of 1,050 permanent employees and pipe production of 303,000 tons (figures in 2011). It is a totally integrated factory; from the raw materials (iron ore, coal, and other materials) to the finished products ductile cast iron pipes of all sizes, from $150 \mathrm{~mm}$ to $2,000 \mathrm{~mm}$ diameters, dedicated to manufacturing a complete range of ductile iron sewerage and potable water pipeline products.

The plant is so immense that it has been divided into five departments to achieve the production, not including supporting services. The Iron and Energy department is composed of Sinter, Iron and Energy workshops, involving around 350 employees in charge of producing sinter mainly composed of iron ores, recycling energy of gas to pre-heat the air in the blast furnace and in the kilns of the Casting 6M and the Casting 7M workshops, producing electricity for the plant, producing liquid cast iron and then supplying it to the Casting departments and the Foundry factory in BLENOD. The 6M Casting department produces pipes whose diameters vary from $150 \mathrm{~mm}$ to $600 \mathrm{~mm}$ in a corporation with 200 people (Note 4). The Large-diameters Casting department is formed of $7 \mathrm{M}$ and $8 \mathrm{M}$ workshops, centrifuging separately pipes from 700 to $1,000 \mathrm{~mm}$ and those from 1,000 to 2,000 mm, with 200 people. Approximately 100 remaining employees work in the Special coatings department and the Storage department. Coatings are done in each casting workshop except for special coatings.

Due to the highly automated, standardized, and repetitive manufacturing process at the plant, the Financial Controlling department has chosen a budgeted controlling system with performance measurements through productivity variance, activity variance and cost variance.

\section{Results and Discussion}

Through the observations it became apparent that it was difficult for all participants to achieve common consent about the OEE's compatibility with the Iron workshop.

The following analysis of results is based on individual interviews with different stakeholders; the data extraction Table 3 shows the principal points. 
Table 3. Results of the individual interviews

\begin{tabular}{|c|c|c|c|}
\hline OEE metric's usefulness & $\begin{array}{l}\text { Incompatibility with the Iron } \\
\text { workshop }\end{array}$ & $\begin{array}{l}\text { Other difficulties related to OEE } \\
\text { and WCM }\end{array}$ & Suggestions \\
\hline $\begin{array}{l}\text { Evaluating equipment } \\
\text { performance }\end{array}$ & $\begin{array}{l}\text { Complicated to determine the purely } \\
\text { theoretical optimum speed of the blast } \\
\text { furnace }\end{array}$ & $\begin{array}{l}\text { Personnel's resistance to change, } \\
\text { intensified by the corporate culture }\end{array}$ & $\begin{array}{l}\text { To deal with staff's } \\
\text { resistance }\end{array}$ \\
\hline $\begin{array}{l}\text { Accessible to operators and } \\
\text { managers }\end{array}$ & $\begin{array}{l}\text { Possibly higher cost may occur if the } \\
\text { blast furnace runs at its maximum } \\
\text { capacity }\end{array}$ & & \\
\hline $\begin{array}{l}\text { Mapping out "losses } \\
\text { landscape" }\end{array}$ & $\begin{array}{l}\text { Prospect of making cost-savings } \\
\text { through working efficiently does not } \\
\text { exist due to the continuous flow }\end{array}$ & Frame of mind: focus on marks & \\
\hline Revealing existing problems & $\begin{array}{l}\text { The demand for cast iron is always } \\
\text { below the optimum yield of the blast } \\
\text { furnace }\end{array}$ & & $\begin{array}{l}\text { To simplify deployment } \\
\text { process related to } \\
\text { administration }\end{array}$ \\
\hline $\begin{array}{l}\text { Initiating corrective or } \\
\text { preventive action }\end{array}$ & $\begin{array}{l}\text { There is seldom blast furnace } \\
\text { breakdown }\end{array}$ & Administrative burdens & \\
\hline $\begin{array}{l}\text { Continuous improvement } \\
\text { perspective }\end{array}$ & $\begin{array}{l}\text { Two mixers of cast iron serve as } \\
\text { buffers }\end{array}$ & & \\
\hline $\begin{array}{l}\text { Releasing managers from the } \\
\text { short-term vision imposed by } \\
\text { budgeted planning }\end{array}$ & $\begin{array}{l}\text { OEE tool is unable to measure the } \\
\text { workshop performance }\end{array}$ & $\begin{array}{l}\text { Data accuracy is low due to } \\
\text { manual data entry }\end{array}$ & $\begin{array}{l}\text { Automated data collection } \\
\text { systems guarantee integrity } \\
\text { of information }\end{array}$ \\
\hline
\end{tabular}

\subsection{Shared Opinion: OEE Metric Is a Useful Tool}

All interviewees, including the production managers, the two WCM coordinators and the plant's financial controller, shared their opinion that the OEE metric is a useful tool.

For them, the OEE tool evaluates equipment performance, which could provide a basis for further improvement. It maps out the "losses landscape"; speed loss, machine breakdown and minor stoppages, defect loss, and so on. All those details are integrated into the single tool. OEE analysis makes it possible to initiate improvement projects and tackle different losses. The OEE metric makes it possible to respond to the questions: Is the equipment effective? If poor performance exists, where does it come from? What are the principal losses? Which actions should be taken to solve the problems and to improve the performance?

For the WCM coordinator of the Iron and Energy department, it is necessary to overcome the constraints imposed by budgeted production planning through the OEE measure as the traditional budgeting prevents the identification of the real optimum equipment yield and achievement of potential improvement, as well as limiting production managers' vision in the short term (for example, meeting the annual cost target is the objective).

As indicated by the manager of the Sinter workshop and the WCM coordinator of the factory, OEE values can be calculated on a daily basis, and it is then possible to monitor and measure the performance frequently. Both of the production managers confirmed their interest in automated data collection to compute OEE values in real time, which is very helpful to avoid manual entry, to guarantee data accuracy and to indicate corrective or preventive action.

\subsection{Issues Regarding WCM at the Plant PAM}

In the context of the depression, according to Saint-Gobain Registration Document 2012, p.51, the Group has made considerable economies in 2012 thanks to the deployment of the new cost-cutting program. WCM consists in this project's materialization, especially for the reduction of operational expenses. The decision has been made to continue and extend it in 2013, for Saint-Gobain group.

Specifically, at the plant the personnel have been assigned to materialize WCM following the top-down strategy defined by the Group. Besides the human intrinsic anxiety about the change due to the long corporate history, the solid industrial structure, and the leading position in the market throughout the company's history, the matter of how to persuade the personnel to gain their productivity through a new project constitutes a great issue. "We have known how to improve our performance for a long time" is a popular answer. Most of them have worked for more than twenty years at the plant and have become experts in their field. Following the economic crisis, the 
creation of a full-time job has been blocked since 2011 and many departments face the problem of staff aging. For the majority of personnel, WCM is considered as a program to question their traditional best practices.

Finally, the administrative burdens remain a constraint for the further evolution of WCM at the plant. Production managers, financial controllers and other employees, having been engaged by WCM, complained about having a series of reports to fill in, and considerable meetings to attend and prepare for, which consumed a lot of time. As indicated by the plant's financial controller, there is also the question of organization; some project has been introduced without achieving cost deployment, while the latter is essential to convince the personnel to follow the project.

The abovementioned difficulties could partly explain the fact that even though the program WCM started in 2009 , the project is still a work in progress at the plant.

The president of the Construction Products Sector said: "WCM is a model for the mindset it encourages, the sharing of best practices and the active participation of all our employees" (cf. WCM policy for the Construction Products Sector). In the public notice of the plant trade union, the management has admitted that the principal benefit of WCM is especially to encourage staff to record the processes, which has not traditionally happened in the plant. There is an interesting argument that the WCM coordinator of the plant put forward during the interview - "The objective of WCM is not to question all practices but to improve them". It is indispensable to make great efforts through internal communication to deliver clearly the message - through $\mathrm{WCM}$, it is of no interest to undergo a revolution, but it is important to record all practices and improve them; to become a continually learning company and to gain sustainable competitiveness. It is also important to raise the personnel's awareness of worldwide growing competition, thus preventing them from resting on their laurels. This kind of process is to convert the top-down strategy into a bottom-up approach.

\subsection{OEE Metric Is not Compatible with the Iron Workshop}

After reviewing the arguments put forward by different stakeholders, the researchers consider that the OEE metric is not compatible with the Iron workshop performance measurement.

The essential purpose for implementing the OEE metric in a production line is to measure the equipment's effectiveness and to identify different losses for further improvement projects. This may be universally true except for the Iron workshop.

Firstly, the blast furnace runs 24 hours a day, 7 days a week; it is a totally continuous flow. The same working manner is applied to the personnel. As a result, regardless of the cast iron tons required, the loading time of the Iron shop remains the same. Little cost-savings could be achieved through running more rapidly, as the blast furnace cannot be stopped and the personnel couldn't be reduced. On the contrary, higher costs may occur due to much greater consumption of materials. For the plant's financial controller, the majority of the expenses are fixed costs. Hence, the improvement potential of the OEE metric for making economies through more efficient performance is not applicable at the Iron workshop.

Secondly, the internal demand for cast iron is always below the optimum capacity of the blast furnace. Because of this, the demand could always be satisfied. The capacity for meeting the demand is not in question. As analyzed by the plant's financial controller, for the Iron workshop, one principal source of productivity gain is to make the cast iron with relatively low cost. It is not possible to achieve it through the OEE metric.

The next point is that breakdown of the blast furnace does not exist. The blast furnace runs all day, every day. There is no danger of breakdown and it is only stopped by the workshop during holidays. In case of a problem with a plunger or conveyor belt, there is little impact on iron production and there is only the replacement or repair cost.

Furthermore, between the Iron workshop and its customers exist the buffers: two mixers, with a storage capacity of 1,200 tons of cast iron. The buffers could minimize the impact of potential breakdown or minor stoppages at the Iron workshop.

Finally, as indicated by Scott and Pisa (1998), the gains in OEE, while important and ongoing, are insufficient because the machine is isolated. They indicate that the manufacturing process is a complex web of interactions between process tools, materials, machines, people, departments, companies, and processes. This is exactly the case of the Iron workshop: considerable interactions between materials' qualities, prices, the three Casting workshops and the Foundry, the Purchase department, etc. For example, potential losses identified by the OEE metric may come from the demand fluctuation instead of a poor performance.

Therefore, the OEE (overall equipment effectiveness) metric is not able to measure correctly the blast furnace 
performance; neither is it able to represent the workshop productivity.

The WCM coordinator of the Iron and Energy department also agreed with this view, although he considered that it should be possible to apply the OEE metric at the Iron workshop. First of all, due to a lack of any breakdowns track, the OEE metric could allow the Iron workshop to reveal details, to discover some problems and to improve the equipment's effectiveness. However, the OEE measure here serves as a breakdown track, and it is no longer a metric of overall equipment effectiveness. Other difficulties indicated by the WCM coordinator may have an impact on the OEE's failure at the workshop. Nevertheless, he mainly put forward the necessity for the OEE metric but did not elaborate enough about how it could be possible to define it for the workshop. The essential point is that the OEE metric fails to measure exactly either the blast furnace's performance or the workshop's productivity. For this reason, the production managers indicated that they have no interest in using the tool.

Based on the above analysis, the following conclusion is drawn: the OEE metric is not compatible with the Iron workshop.

\subsection{Data Accuracy: Essential for OEE Metric Reliability}

According to Muchiri and Pintelon (2008), the validity and usefulness of the OEE measure are highly dependent on the data collection and accuracy.

Both of the production managers confirmed this view. For the manager of the Sinter workshop, it is important to record every detail in order to work effectively with the OEE metric. It is also more likely to be achieved with a supervision system compared to manual data entry. The latter usually leads to unidentified loss due to workers' carelessness. If the unidentified losses are higher than 3\% of all losses, OEE analysis is no longer reliable. For the manager of the Iron workshop, an automated data collection system is an ideal performance measurement tool to understand the workshop's productivity, to identify different losses and to target actions for improvement. For the moment, the plant has a data collection and analysis tool named Base TRS (OEE basis), provided by the consulting firm. It is developed in ACCESS: the data collection remains in the form of manual entry while the analysis of different losses is an automated process.

Hence, data collection and accuracy are challenges to the OEE measure's reliability.

\section{Conclusion}

Throughout this paper, we have sought to analyze the OEE metric's application range in real manufacturing lines, especially focusing on identifying where challenges exist. We have studied it with the qualitative research method to analyze the interest in the OEE performance-measurement tool; to understand why it is awkward to implement it in some workshops; to respond to our research question "Is Overall Equipment Effectiveness (OEE) universally applicable?" while discovering the OEE metric's limitations; and to identify potential difficulties that should be taken into consideration for its successful deployment.

Both the literature review and the practitioners' opinions have shown that traditional budgeting has the following constraints: the past-based planning continues to hide some problems and prevents the company from revealing the optimum performance of equipment; the focus on meeting the annual budget restricts the vision of production managers and management. As a result, the firm's long-term competiveness may be attenuated merely attempting to become better than in the past is not sufficient. Traditional cost accounting systems, developed for mass production, need to be updated to accommodate lean manufacturing. Finally, with existing financial measures, it is not possible to take into account some nonfinancial metrics which are critical to the firm's long-term survival according to production managers.

It is concluded that the OEE measure, a technical ratio related to equipment effectiveness, is able to overcome the above limitations; it releases managers from the short-term vision imposed by budgeted planning and provides the perspective of continuous improvement towards perfection. It evaluates machine performance by taking into account three factors essential to equipment effectiveness - availability, speed and quality; it also unmasks the entire machine performance losses and indicates potential corrective or preventive action. Moreover, it is accessible to operators and managers; and finally, it is possible to monitor the performance frequently with this tool.

Nevertheless, the fact that the Iron workshop had attempted to deploy the OEE metric but had finally decided not to use it provided the principal materials for our conclusion: the OEE measure is not universally applicable. This stems from its distinct manufacturing nature: it is complicated to determine the purely theoretical optimum speed of the blast furnace; it operates at the continuous round-the-clock flow; the internal customers' demand is always below the maximum capacity of the workshop; important breakdown does not exist and minor stoppages have 
little impact on production; and two mixers serve as buffers to minimize the breakdown impact. As a consequence, the potential for making economies through performing effectively does not exist; the losses identified by the OEE measure are false as they are not due to poor performance, but related to demand fluctuation. Therefore, the OEE metric fails to indicate the true productivity of the workshop.

The exception at the Iron workshop does not invalidate the OEE metric's usefulness for manufacturing performance measurement and improvement. The success at the Special Coatings department has shown that the OEE measure is beneficial to their progress. The case study has also shown that it is necessary for an industrial financial controller to understand manufacturing settings and to take into account important non-financial metrics to assist production managers in their decision-making.

From the empirical analysis, three kinds of challenges have been identified that should be considered before deploying the OEE metric. First of all is data accuracy. The reliability of the OEE values depends highly on data integrity. Due to the low accuracy of manual data collection, it is important to invest in an automated supervision system not only to improve the data's reliability but also to monitor and assess the performance more frequently.

Another potential difficulty is the personnel's resistance to change. It is essential to devote great efforts to internal communication and to make the message understood: the purpose of lean manufacturing is not simply to question all practices, but to improve current performance, to convert the firm into a continually learning company and to gain sustainable competitiveness.

The third point is to simplify the project deployment process related to administration. Otherwise, the administrative burden could increase the dissatisfaction of the personnel.

Finally, we would like to revise the Toyota Production System, which is rooted in distinctive Japanese features. The principle of "Reduction of cost through elimination of waste" resulted from the lack of natural resources in Japan. Furthermore, "Japanese diligence, [a] high degree of ability and favored labor environment" contributed to the second principle - "To make full use of the workers' capabilities". With a lack of those features, it is possible that the staff in occidental firms have fewer crises of confidence, preventing them from understanding the importance of continually learning and becoming lean. The global depression may contribute to the personnel's awareness of worldwide growing competition and these two lean principles. Nevertheless, in our empirical analysis, the costly consulting service has intensified the personnel's resistance. It is a complex issue which needs to be confirmed by further research studies.

This article is limited by the narrowness of the single case study at the Iron workshop. Further research should explore the application of OEE in varied manufacturing settings and investigate issues related to automated data-collection systems and personnel's resistance.

\section{References}

Bhimani, A., Horngren, C. T., Datar, S. M., \& Foster, G. (2008). Management and cost accounting. Harlow: Pearson Education.

Bulent, D., Tugwell, P., \& Greatbanks, R. (2000). Overall equipment effectiveness as a measure of operational improvements-a practical analysis. International Journal of Operations \& Production Management, 20, 1488-1502. http://dx.doi.org/10.1108/01443570010355750

Ericsson, J. (1997). Disruption Analysis-An Important Tool in Lean Production. Department of Production and Materials Engineering, Lund University: Lund.

Fleischer, J., Weismann, U., \& Niggeschmidt, S. (2006). Calculation and optimization model for costs and effects of availability relevant elements. In Proceedings of LCE2006.

Hayes, R. H., Wheelwright, S. C., Clark, K. B., \& Kaplan, R. S. (1989). Measuring manufacturing performance. McKinsey Quarterly, 4, 73-82.

Horngren, C. T., \& Foster, G. (2008). Cost Accounting: a Managerial Emphasis (13th ed.). Englewood Cliffs, NJ: Prentice-Hall International.

Huang, S. H., Dismukes, J. P., Shi, J. J., Qi, S., Razzak, M. A., Bodhale, R., \& Robinson, D. (2003). Manufacturing productivity improvement using effectiveness metrics and simulation analysis. International Journal of Production Research, 41(3), 513-527. http://dx.doi.org/10.1080/0020754021000042391

Kaplan, R. S. (1984). The Evolution of Management Accounting. The Accounting Review, 59(3), 390.

Kaplan, R. S. (1990). Measures for Manufacturing Excellence. Boston: Harvard Business School Press.

Karmarkar, U. S. (1989). Getting control of just-in-time. Harvard Business Review, 67, 122-131. 
Konopka, J. M. (1996). Improvement output in semiconductor manufacturing environments. PhD Dissertation, Department of Industrial Engineering, Arizona State University.

Muchiri, P., \& Pintelon, L. (2008). Performance measurement using overall equipment effectiveness (OEE): literature review and practical application discussion. International Journal of Production Research, 46(13), 3517-3535. http://dx.doi.org/10.1080/00207540601142645

Nakajima, S. (1988). Introduction to TPM: Total Productive Maintenance. Cambridge, MA: Productivity Press.

Scott, D., \& Pisa, R. (1998). Can overall factory effectiveness prolong Moores law: ElectroIQ. Solid State Technol, 41, 75-82.

Sugimori, Y., Kusunoki, K., Cho, F., \& Uchikawa, S. (1977). Toyota production system and Kanban system Materialization of just-in-time and respect-for-human system. International Journal of Production Research, 15(6), 553. http://dx.doi.org/10.1080/00207547708943149

\section{Notes}

Note 1. The largest association of management accountants in the UK.

Note 2. Iron and Energy department is composed of Sinter workshop, Iron workshop and Energy workshop. Sinter workshop is in DIEULOUARD; the others are in PONT-A-MOUSSON.

Note 3. Figure source: SAING-GOBAIN PAM Intranet http://portalng.saint-gobain.com/fr/web/sgpam

Note 4. Figures related to the personnel were provided by the financial controller of the Plant PAM.

\section{Copyrights}

Copyright for this article is retained by the author(s), with first publication rights granted to the journal.

This is an open-access article distributed under the terms and conditions of the Creative Commons Attribution license (http://creativecommons.org/licenses/by/3.0/). 